
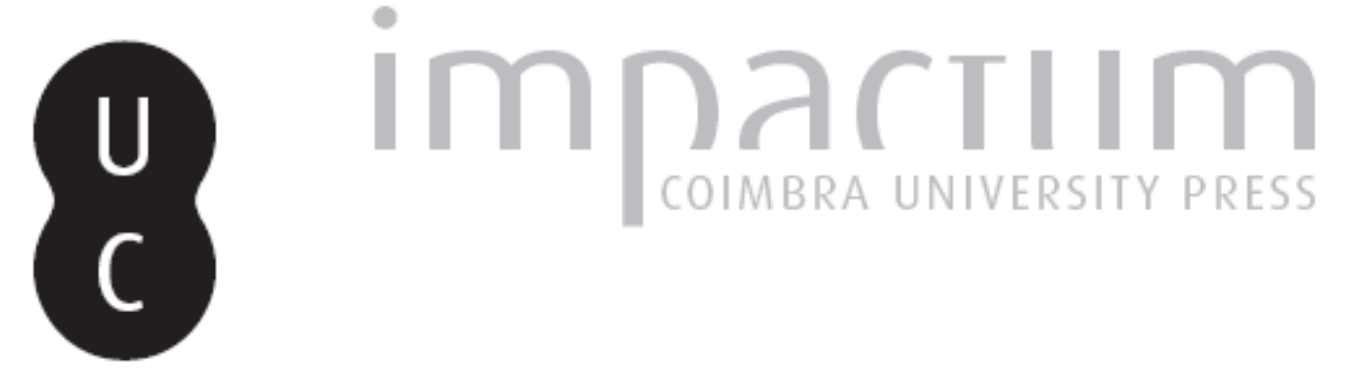

Política de cidades, requalificação urbana e património: o caso do Polis de Leiria

Autor(es): $\quad$ Silva, Ana Marina Ribeiro; Carvalho, Paulo

Publicado por: $\begin{aligned} & \text { Faculdade de Letras da Universidade de Coimbra, Departamento de } \\ & \text { Geografia }\end{aligned}$

URL

persistente:

URI:http://hdl.handle.net/10316.2/30278

DOI:

DOI:http://dx.doi.org/10.14195/0871-1623_31_23

Accessed : $\quad$ 26-Apr-2023 12:08:48

A navegação consulta e descarregamento dos títulos inseridos nas Bibliotecas Digitais UC Digitalis, UC Pombalina e UC Impactum, pressupõem a aceitação plena e sem reservas dos Termos e Condições de Uso destas Bibliotecas Digitais, disponíveis em https://digitalis.uc.pt/pt-pt/termos.

Conforme exposto nos referidos Termos e Condições de Uso, o descarregamento de títulos de acesso restrito requer uma licença válida de autorização devendo o utilizador aceder ao(s) documento(s) a partir de um endereço de IP da instituição detentora da supramencionada licença.

Ao utilizador é apenas permitido o descarregamento para uso pessoal, pelo que o emprego do(s) título(s) descarregado(s) para outro fim, designadamente comercial, carece de autorização do respetivo autor ou editor da obra.

Na medida em que todas as obras da UC Digitalis se encontram protegidas pelo Código do Direito de Autor e Direitos Conexos e demais legislação aplicável, toda a cópia, parcial ou total, deste documento, nos casos em que é legalmente admitida, deverá conter ou fazer-se acompanhar por este aviso.

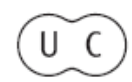




\title{
Política de cidades, requalificação urbana e património - o caso do Polis de Leiria
}

\author{
Ana Marina Ribeiro Silva \\ Mestre em Geografia Humana, Ordenamento do Território e Desenvolvimento pela Universidade de Coimbra. \\ aninha_bv@hotmail.com
}

\section{Paulo Carvalho}

Departamento de Geografia e Centro de Estudos de Geografia e Ordenamento do Território (CEGOT). Faculdade de Letras da Universidade de Coimbra. paulo.carvalho@fl.uc.pt

\section{Resumo:}

Os territórios urbanos acompanham os novos paradigmas de desenvolvimento e mudança no contexto de desígnios que pretendem promover territórios mais coesos, competitivos, atrativos e com valor económico e cultural.

A requalificação urbana, como instrumento incontornável da sustentabilidade urbana e processo estratégico, envolve a articulação e integração de diversas componentes, reflete a tendência para a reutilização de infraestruturas e equipamentos existentes, e constitui uma oportunidade para salvaguardar e valorizar o património.

Esta matriz teórica será aprofundada através de um estudo de caso (a cidade de Leiria) relacionado com a implementação do Programa Polis, no sentido de analisar os efeitos ao nível da organização espacial, da salvaguarda e valorização do património, e da perceção e vínculos por parte dos cidadãos que vivem e utilizam os territórios intervencionados.

Palavras-chave: Política de Cidades. Requalificação Urbana. Património. Polis. Leiria.

\section{Resumé:}

Politique de villes, requalification urbaine et patrimoine - le cas de Polis de Leiria

Les territoires urbains accompagnant les nouveaux paradigmes du développement et de changement dans le contexte de modèles qui visent à promouvoir les territoires plus compétitifs, plus attrayants et plus cohérents, avec la valeur culturelle et économique.

La requalification urbaine, comme un instrument essentiel de la durabilité urbaine et des processus stratégiques, implique l'articulation et l'intégration des différentes composantes, reflète la tendance à la réutilisation des équipements existants et des infrastructures et offre la possibilité de sauvegarder et d'améliorer le patrimoine.

Cette matrice théorique va être renforcée grâce à une étude de cas (la ville de Leiria) liée à la mise en œuvre du Programme Polis, afin d'analyser les effets du niveau d'organisation spatiale, de protection et de mise en valeur du patrimoine et de la perception et de liens pour les citoyens qui vivent et qui utilisent les territoires d'intervention.

Mots-clés: Politique des Villes. Requalification Urbaine. Patrimoine. Polis. Leiria.

\section{Abstract:}

Politic of cities, urban requalification and heritage - the case of Polis of Leiria

The urban territories accompany new paradigms of development and change in the context of designs which aim to promote the territories more competitive, attractive and cohesive, with cultural and economic value.

The urban requalification, as essential instrument of urban sustainability and strategic process, involves the articulation and integration of various components, reflects the trend toward re-use of existing equipment and infrastructure, and presents an opportunity to safeguard and enhance the heritage.

This theoretical matrix will be deepened through a case study (the city of Leiria) related to the implementation of the Polis Programme, in order to analyse the effects of spatial organization level, safeguarding and enhancement of heritage and perception and links for citizens who live and use the intervention areas.

Keywords: Politic of Cities. Urban Requalification. Heritage. Polis. Leiria. 


\section{Política de cidades, requalificação urbana e património}

A política de cidades pretende fomentar uma nova forma de governar através da planificação de estratégias de ação, ou seja, a política de cidades é definida através de um quadro conceptual de utilização e organização nas cidades que se articula em função de diversos processos estratégicos, como é o caso do planeamento.

Através do planeamento torna-se exequível (re) pensar as cidades em função das características físicas e dos elementos simbólicos que estabelecem uma ligação com o passado e despertam sentimentos de pertença. Além do planeamento, importa destacar a requalificação urbana como processo planeado que pretende a valorização e competitividade das cidades, a salvaguarda e a valorização de elementos (humanos e naturais) considerados fulcrais para a construção e a perceção da imagem, e para a consolidação da identidade individual ou coletiva (SILVA, 2011).

Atendendo às novas territorialidades, o património assume-se como um componente decisivo e estratégico na requalificação urbana e, deste modo, uma dimensão fundamental para a qualificação e a valorização da paisagem urbana.

Os territórios urbanos acompanham os novos paradigmas de desenvolvimento e mudança no contexto de desígnios que pretendem promover territórios mais coesos, competitivos, atrativos e com valor económico e cultural. Neste sentido de preocupação, a partir do final do último século os ambientes urbanos têm revelado necessidade de encontrar um quadro conceptual de ferramentas de ação que se coadunem com os desequilíbrios territoriais existentes.

De forma recorrente os processos de crescimento e desenvolvimento das cidades apresentam um carácter desordenado, desorganizado e disfuncional, traduzindo-se por uma morfologia inaceitável e irracional. Além dos problemas no ambiente físico, para que a cidade "(...) comece a ser entendida como um projecto para um novo estilo de vida, pressupõe atenuar ou resolver problemas como o ruído, melhorar a qualidade do ar, conciliar a salvaguarda e valorização do património edificado com as operações de renovação e reabilitação urbana, proteger e ampliar os espaços verdes, requalificar e revitalizar espaços abandonados e degradados, como antigas instalações industriais, troços ferroviários desactivados, sectores urbanos devolutos e insalubres, entre outros. Portanto, é necessário considerar uma visão integral do desenvolvimento urbano" (CARVALHo, 2008: 328-329).
Nos últimos anos as cidades tiveram que se adaptar a um novo paradigma de mudança baseado na competitividade territorial. Para tal, iniciou-se um período de elaboração e implementação de políticas de desenvolvimento com viabilidade técnica, financeira e económica, designadas de política de cidades, privilegiando atores públicos e privados. Deste modo, as cidades têm que saber tirar vantagens competitivas dos instrumentos consagrados na política de cidades, e que, surge com o objetivo de atenuar os impactes provocados pelas atividades humanas, reorganizar o espaço de forma sustentável, inclusiva, coesa e coerente e valorizar e fortalecer o ambiente urbano. A política de cidades contribui para a criação de modelos de autossustentação, a fim de ajudar as cidades e que estas se ajudem a si próprias a individualizarem e valorizarem-se de forma integrada incrementando uma nova forma de governação baseada num conjunto de estratégias de ação que se articulam em função de diversos processos estratégicos, como é o caso da requalificação urbana. Segundo a Direção Geral de Ordenamento do Território e Desenvolvimento Urbano, a requalificação urbana consiste na "(...) operação de renovação, reestruturação ou reabilitação urbana, em que a valorização ambiental e a melhoria do desempenho funcional do tecido urbano constituem objectivos primordiais da intervenção. (...) A valorização ambiental e a melhoria da qualidade do espaço urbano são normalmente abordadas numa dupla perspectiva: de resolução de problemas ambientais e funcionais (...) e a criação de factores que favoreçam a identidade, a habitabilidade, a atractividade e a competitividade das cidades ou áreas urbanas específicas" (DGOTDU, 2008: 67).

Uma nova visão de cidade sustentável e com sensibilidade ambiental começa a emergir e através de programas urbanos (como, por exemplo, o Polis) são incluídas ferramentas de ação, tal como a requalificação urbana, que tem como objetivo fomentar a qualidade de vida e a saúde ambiental nos espaços urbanos. As cidades, ao usufruírem de programas de intervenção urbana, podem promover a inclusão e coerência social, ajudar a realçar a necessidade de melhorar a qualidade ambiental adotando estratégias eficazes de gestão de recursos, incutir o sentido de identidade, consciencializar a população para a preservação do potencial da cidade (elementos simbólicos que estabelecem a ligação com o passado, que despertam o sentido de pertença e que promovem e reavivam as memórias), bem como ainda aumentar a competitividade empresarial $e$ comunitária. Neste sentido de preocupações, a requali- 
ficação urbana surge como um processo auxiliar e fundamental na política de cidades, com caráter planeado, contínuo e dinâmico, baseado num conjunto de regras e imposições que permitem melhorar, corrigir a desarticulação territorial e valorizar as cidades e os recursos existentes (SILVA, 2011).

De modo, a (re)criar o ambiente urbano desejável, as intervenções urbanas devem incidir na criatividade e inovação dos recursos humanos dos atores locais (públicos e/ou privados) a fim de operacionalizar os projetos no tecido físico e social das cidades e a assegurar o progresso e a competitividade. Ou seja, pretende (re)organizar a estrutura morfológica da cidade e a permanente defesa dos sistemas naturais, que são essenciais para a divulgação de um padrão de vida coerente e sustentado, bem como garante a preservação dos elementos identitários, em torno dos quais se geram condições de convivência quotidiana, e que confirmam os valores atuais e do passado de uma sociedade.

A requalificação urbana, como processo estratégico, envolve a articulação e integração de diversas componentes como, por exemplo, a habitação, a cultura, a coesão social, o espaço público, a mobilidade, e reflete a tendência para a reutilização das infraestruturas e equipamentos existentes, isto é, revela a primazia pela recuperação/reconversão de espaços e edifícios (devolutos, abandonados ou degradados), a valorização da imagem e a sua divulgação para o exterior. Esta tendência de intervenção urbana, permite diferenciar os sistemas urbanos, bem como contribui ainda para o surgimento de novas áreas de sociabilidade e o estímulo pelo sentido de pertença, de filiação e de vínculo ao território, por parte da população. 0 território vai-se organizando de forma complexa assumindo novas geografias e novas territorialidades que se traduzem numa paisagem mais equilibrada, consolidada e de acordo com a realidade física e histórica (Silva, 2011).

Neste sentido, a paisagem deve ser vista como uma impressão digital que transporta a história de um território e de uma sociedade. Deste modo, deve ser garantida a proteção dos valores associados à paisagem, uma vez que a existência de património contribui para que um território ganhe valor cultural, representando, assim, um desafio para a competitividade territorial.

No contexto da política de cidades, e de acordo com esta perspetiva, os programas urbanos permitem não só valorizar o território mas também o património (e os seus significados ou qualidades como o valor económico, artístico ou estético e cognitivo ou de memória). Este deve ser salvaguardado, valorizado e divulgado pois permite uma constante ligação do passado com o presente, possibilita distinguir e afirmar as identidades geográficas e representa a herança de uma sociedade, quer-se com isto dizer, que o património remete para o percurso histórico-cultural, socioeconómico e político.

De acordo com Henriques (2004: 3), "a coerência e continuidade das identidades individuais e coletivas, nos vários níveis de identificação, (...), depende da preservação das heranças históricas, materiais e imateriais, que conferem carácter aos lugares e diferenciam as comunidades humanas".

Os elementos simbólicos assumem-se ainda como um componente estratégico e decisivo nas intervenções urbanas pois, ao serem alvo de programas que permitem a sua requalificação, conservação e/ou reconversão, potencializam e dinamizam um território, ou seja, permitem a afirmação de um território, através de (novas) funcionalidades, e da economia mediante o relançamento da atividade económica e na criação de emprego. Tal como refere Carvalho (2000: 199), "a (re)descoberta dos territórios e dos seus valores patrimoniais são hoje condições basilares na construção de novas identidades e na identificação de alternativas de desenvolvimento (dos territórios e das populações)". Sabendo que a população é considerada como um agente ativo na construção e difusão do património, é necessário incutir-lhe o sentido de corresponsabilização patrimonial, a fim de potencializar uma correta gestão e fruição. Deste modo, torna-se possível transmitir uma imagem atrativa para o espaço exterior, onde o património "funciona" como testemunho vivo, que distingue e individualiza um território como único.

\section{Orientações e estratégias de intervenção: da União Europeia a Portugal}

A política urbana acompanhou e internalizou as preocupações em matéria de cidade e ambiente urbano, e as tendências decorrentes das novas exigências em matéria de desenvolvimento e inserção dos lugares na nova ordem global, de tal forma que configura uma plataforma dinâmica de preocupações em matéria de qualidade de vida, competitividade e governação (CARVALHO, 2008).

Na União Europeia podemos assinalar diversos documentos orientadores (tendo em vista influenciar a estruturação e a implementação de políticas integradas de desenvolvimento urbano) aprovados em especial 
nas últimas duas décadas, como, por exemplo, o Livro Verde sobre o Ambiente Urbano (1990), o relatório Cidades Europeias Sustentáveis (1998), a Nova Carta de Atenas (2003), ou seja, a visão do Conselho Europeu de Urbanistas sobre as cidades do século XXI, a Carta de Leipzig para as Cidades Europeias Sustentáveis (2007) e a Agenda Territorial da União Europeia (2007).

A revisão da Agenda Territorial da União Europeia, ou o ajuste às mudanças relacionadas com a nova conjuntura económica e social, e com o contexto do Tratado de Lisboa, conduziu a União Europeia a adotar, em 19 de maio de 2011, a designada Agenda Territorial 2020, que definiu seis prioridades territoriais para o desenvolvimento, a saber: promover o desenvolvimento territorial policêntrico e equilibrado; estimular o desenvolvimento integrado nas cidades, no meio rural e em áreas específicas; integrar no plano territorial as regiões funcionais transfronteiriças e transnacionais; assegurar a competitividade global das regiões baseada em economias locais fortes; melhorar a conectividade territorial para os indivíduos, comunidades e empresas; gerir e interligar os valores ecológicos, paisagísticos e culturais das regiões.

As grandes linhas estruturantes e orientadoras do desenvolvimento urbano, como a melhor articulação das políticas sectoriais com incidência urbana, a integração das dimensões económica, social e ambiental nas políticas urbanas, o desenvolvimento da cooperação e de um novo sentido de responsabilidade na gestão de políticas urbanas, configuram temáticas cada vez mais relevantes para os processos de planeamento estratégico (CARVALHo, 2012).

A implementação de políticas urbanas em Portugal com preocupações ao nível do planeamento urbano começa a emergir entre a década de 80 e a década de 90 , coincidindo com a implementação do Quadro Comunitário de Apoio I (QCA I). Segundo Queirós e VALE (2005: 6), "(...) não foi contemplada qualquer intervenção desenhada especificamente para a requalificação das cidades no I QCA (1989-1993), situação que de alguma forma se altera com o II QCA (1994-1999), designadamente através da criação de um Programa Operacional para o Ambiente e Revitalização Urbana”.

O sucesso da intervenção no âmbito do projeto urbano EXPO 98, com a modernização e a polarização de uma área ribeirinha que se encontrava degradada e marginalizada, através de uma estratégia de ação inovadora, vai constituir uma referência para o planeamento e a implementação de iniciativas urbanas no novo período de programação das políticas públicas (2000-2006), com o apoio da União Europeia, como é o caso do Programa Polis (criado através da Resolução do Conselho de Ministros $n^{\circ} 26 / 2000$, de 15 de maio).

O principal objetivo do Polis (Programa de Requalificação Urbana e Valorização Ambiental das Cidades) consiste em melhorar a qualidade de vida nas cidades, através de intervenções nas vertentes urbanística e ambiental, e deste modo melhorar a atratividade $e$ competitividade de polos urbanos que desempenham um papel relevante na estruturação do sistema urbano nacional. O Polis pretende desenvolver um conjunto de intervenções urbanísticas exemplares, com base em parcerias, especialmente entre as Câmaras Municipais e o Governo, que possam servir de referência para outras a desenvolver pelas autarquias locais, e visa a prossecução dos seguintes objetivos específicos: desenvolver grandes operações integradas de requalificação urbana com uma forte componente de valorização ambiental; desenvolver ações que contribuam para a requalificação e revitalização das cidades e que promovam a sua multifuncionalidade; apoiar outras ações de requalificação que permitam melhorar a qualidade do ambiente urbano e valorizar a presença de elementos ambientais estruturantes tais como frentes de rio ou de costa; apoiar iniciativas que visem aumentar as áreas verdes, promover áreas pedonais e condicionar o trânsito automóvel nas cidades.

A estruturação do Programa Polis desenvolve-se em quatro componentes, cada uma com diversas linhas de intervenção. A Componente 1, orientada para operações integradas de requalificação urbana e valorização ambiental, segundo duas linhas de ação, apoiou diversas iniciativas em quase três dezenas de cidades portuguesas (18 cidades no lançamento do Programa e 10 cidades selecionadas por concurso). A Componente 2 visou realizar intervenções em cidades com áreas classificadas como Património Mundial (Angra do Heroísmo, Évora, Guimarães, Porto e Sintra). A Componente 3 pretendeu a valorização urbanística e ambiental em áreas de realojamento, envolvendo projetos avulsos nas Áreas Metropolitanas de Lisboa e do Porto. A Componente 4 caracterizou-se pela aplicação de medidas complementares para melhorar as condições urbanísticas e ambientais das cidades, e teve aplicação em 7 cidades. Portanto, trata-se de grandes operações integradas de requalificação urbana em 28 cidades e outras intervenções de menor dimensão em 12 cidades.

No que diz respeito aos instrumentos de gestão do Programa, destacam-se os instrumentos de intervenção urbanística (Planos Estratégicos, Planos de Urbanização e Planos de Pormenor) e os instrumentos que concretizam o modelo institucional, com novas formas de 
articulação e parcerias entre o Estado e as Autarquias Locais, através da constituição de sociedades anónimas de capital público.

$\mathrm{Na}$ atualidade as intervenções em contexto urbano têm como suporte fundamental a política de cidades Polis XXI (cofinanciada pelos programas operacionais do Quadro de Referência Estratégica Nacional, 2007-2013). Esta, pretendendo abrir um novo ciclo de intervenção urbana, concretiza-se através do apoio a projetos selecionados em três grandes domínios de intervenção (designados instrumentos de política): parcerias para a regeneração urbana; redes urbanas para a competitividade e inovação; ações inovadoras para o desenvolvimento urbano. 0 primeiro e o terceiro instrumentos de política para a implementação do Polis XXI são os mais relevantes em matéria de requalificação integrada de espaços urbanos. Como metas, até 2015, foram definidas 60 operações de regeneração urbana, 31 cidades envolvidas em redes e 75 projetos inovadores de desenvolvimento urbano (CARVALHO, 2008).

No sentido de analisar os efeitos da implementação do Polis, ao nível da organização espacial, da sal- vaguarda e valorização do património, e da perceção e vínculos por parte dos cidadãos, utilizamos como exemplo a cidade de Leiria.

\section{Leiria: retrato territorial}

Leiria (Figura 1) assume expressão no contexto nacional, em particular quando é associada ao eixo Leiria-Marinha Grande, na medida em que se trata de uma área direcionada para a indústria metalúrgica, para a produção de vidro (cristalaria) e ligada às indústrias dos plásticos e moldes.

No que concerne à dinâmica territorial do sistema urbano nacional, a área em estudo encontra-se numa área dinâmica de expansão do sistema urbano de Lisboa, no limite Norte da Área Metropolitana de Lisboa (AML). Leiria apresenta também articulação com a Área Metropolitana do Porto (AMP) dada a sua posição estratégica entre importantes vias de comunicação e integra ainda a denominada Metrópole do Centro Litoral, tal como Coimbra, Figueira da Foz, Viseu e Aveiro.

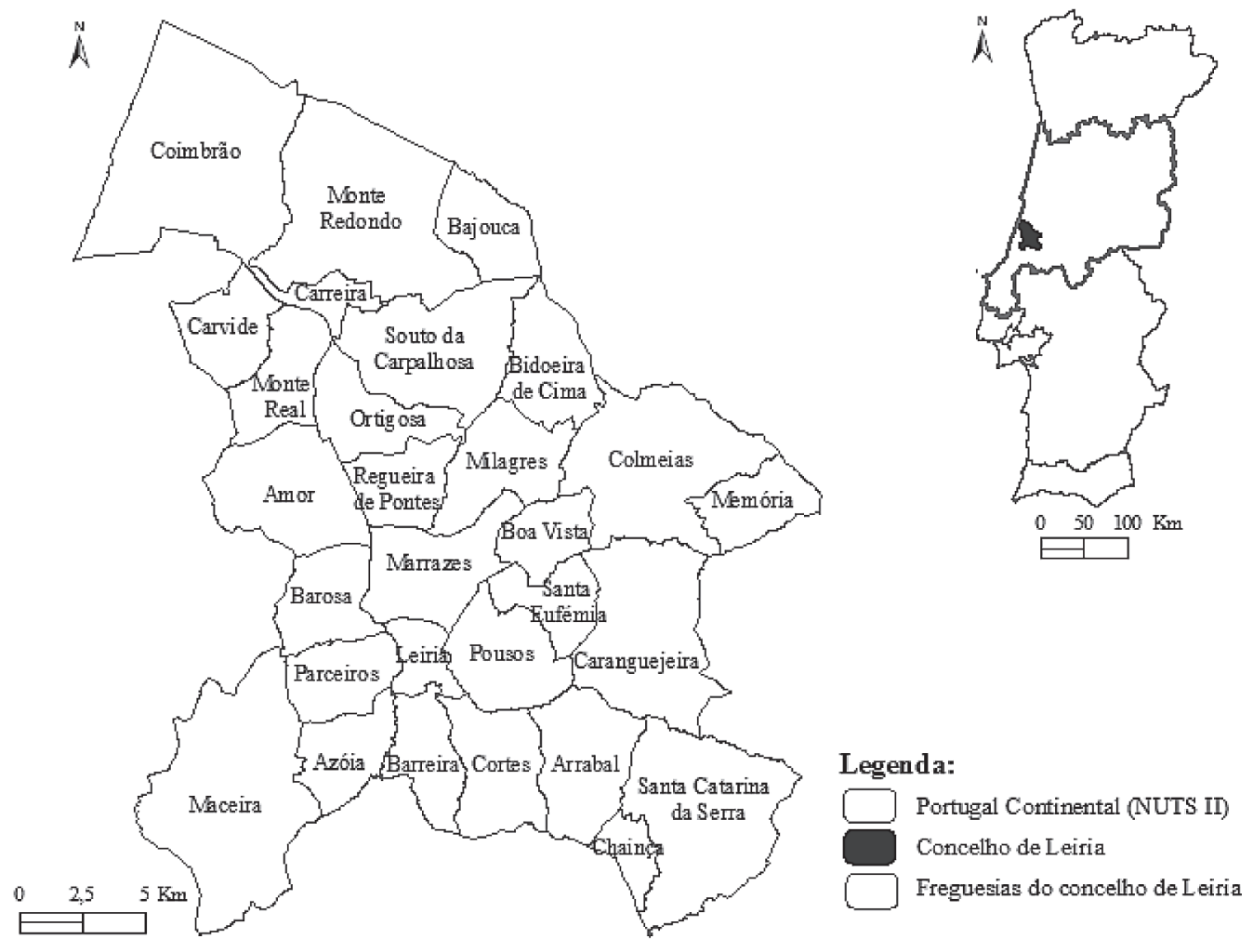

Figura 1

Mapa de localização e divisão administrativa de Leiria

Fonte: SILVA, 2011. 


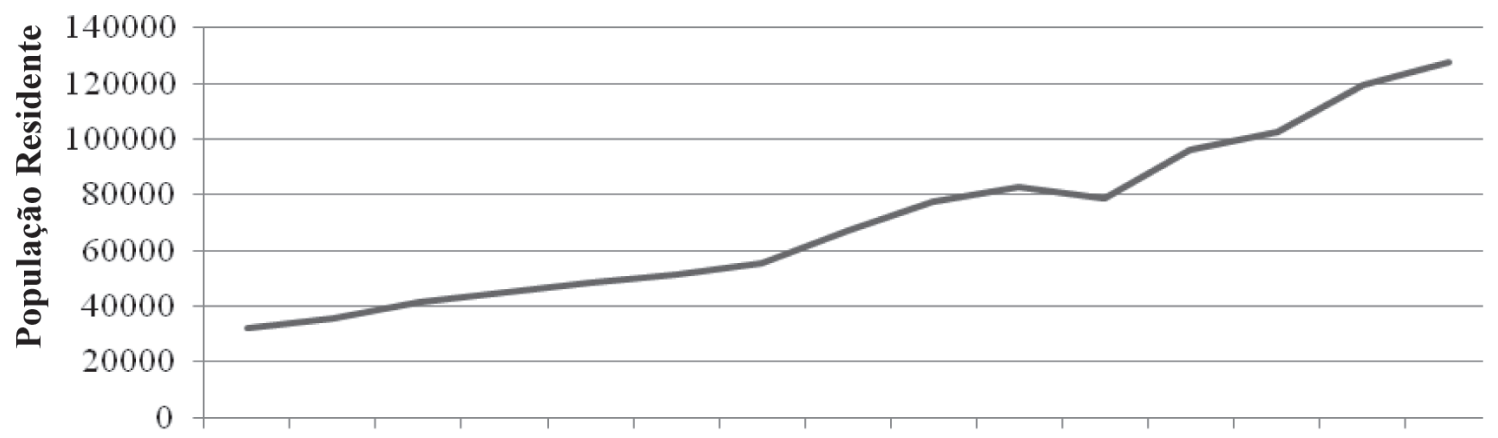

186418781890190019111920193019401950196019711981199120012011

\section{Anos Censitários}

Figura 2

Evolução da população residente no concelho de Leiria (1864-2011)

Fonte: Elaboração própria com base nos dados publicados pelo INE.

O facto de Leiria se encontrar numa área de forte acessibilidade, atravessada por importantes vias de comunicação como é o caso das vias rodoviárias $\mathrm{A} 1, \mathrm{~A} 8$ e A17, pelo itinerário complementar IC2-EN1 e, entre outras pelas estradas nacionais $n .^{\circ} 109, n^{\circ} 113$ e a estrada $n .{ }^{\circ} 242$, que conferem vantagens no que diz respeito às trocas, distribuição e circulação de bens, pessoas e mercadorias. De salientar, a existência da via ferroviária, linha do Oeste, que aparece no concelho de Leiria como um modo de transporte alternativo, mas deficiente.

O concelho de Leiria (sub-região do Pinhal Litoral) encontra-se dividido em vinte e nove freguesias (figura 1), numa área aproximada de 568,02 km² e com um quantitativo populacional de 126.879 habitantes ${ }^{1}$.

A figura 2 permite analisar a evolução da população residente no concelho de Leiria.

Desde o primeiro recenseamento da população em 1864 até 1960 verificou-se um aumento populacional no concelho de Leiria que viria a ser contrariado em 1971. O decréscimo populacional verificado entre 1960 e 1971 "(...) poderá ser explicado pelo início de uma dinâmica migratória nacional para Lisboa e para fora do país, que começou a ter maior expressão no início dos anos 60 e pela Guerra Colonial” (CML, 2004: 11). A tendência para a diminuição da população foi invertida e, na década de 80 , voltou a registar-se um aumento populacional justificado pelo desenvolvimento e expansão da atividade industrial, ligada à produção de vidro, plásticos e dos moldes que atraiu mais população a estas atividades do sector terciário (terciarização da economia e da população). O concelho de Leiria apresenta

1 Os dados de 2011 utilizados têm como suporte os resultados preliminares e provisórios dos CENSOS 2011. uma tendência contínua para o aumento populacional, tal facto resulta do forte investimento verificado no âmbito dos equipamentos de apoio ao ensino, na habitação, nas acessibilidades e na criação de novos postos de trabalho sobretudo no domínio do sector terciário.

Porém a imagem de Leiria está também associada ao castelo, mandado erguer por D. Afonso Henriques (século XII), e ao rio Lis.

Entre o castelo e o rio, nasceu e desenvolveu-se a cidade de Leiria. E é o rio Lis que serve de mote ao Programa Polis ("devolver o rio Lis a Leiria") (CORREIA, 2007: 9), que pretende desenvolver nas cidades a atratividade e a competitividade através de intervenções urbanísticas e ambientais.

\section{Polis Leiria: dos instrumentos operacionais aos resultados das intervenções}

\subsection{Delimitação, objetivos e estrutura do Polis}

A área de intervenção do Programa Polis compreende o centro histórico de Leiria e os espaços envolventes ao rio Lis. O centro histórico de Leiria corresponde à área que se desenvolveu desde o castelo até ao rio (maioritariamente na margem esquerda), ou seja, trata-se de um espaço urbano antigo, densamente ocupado e caracterizado por ruas estreitas, tortuosas e sem saída. Os edifícios nesta área destacam-se pela sua regularidade em termos estéticos e morfologia, conferindo uma malha urbana irregular, típica das cidades ligadas ao tempo medieval.

É evidente que a expansão da cidade de Leiria fez-se ao longo do percurso natural do rio. Porém, nos finais do século $X X$, constatou-se que "(...) o rio Lis foi 
perdendo o estatuto de linha de água estruturante para o desenvolvimento morfológico e económico da cidade através de um abandono geral e até de um desrespeito das suas características como elemento natural. (...) No final do século passado, a cidade cresceu de "costas voltadas" para o seu rio" (SOCIEDADE LEIRIAPOLIS, 2007: 23).

Com a passagem para o século XXI, com o agudizar das preocupações ambientais e com a necessidade sentida em solucionar os problemas urbanos, começou a surgir um novo paradigma de organização do espaço urbano que se diz ser sustentável, gerando intervenções que promovem a coerência entre o urbano e o ambiente.

Em virtude dos problemas urbanos verificados no centro histórico de Leiria, atualmente esta área está a ser alvo de um processo de requalificação que tem por objetivo melhorar a qualidade ambiental, bem como a própria organização do espaço urbano mais antigo da cidade, onde a função habitacional entrou em declínio dada a decadência das condições de habitabilidade. À semelhança do Programa Polis que veio dar novo alento à organização da área urbana, o PALOR (Programa de Acção Local para a Regeneração Urbana do Centro Histórico de Leiria - 2009/2011) "(...) contempla um conjunto de actividades integradas de valorização de áreas de excelência urbana, nomeadamente do centro histórico e da frente ribeirinha do Rio Lis (...)" (CML, 2011: 9). Em ambos os programas é patente uma preocupação em requalificar os espaços públicos que são utilizados diariamente pelos residentes, população que aí se desloca diariamente para trabalhar, mera população que se encontra de passagem ou turistas.

No caso específico do Programa Polis em Leiria, este "(...) assentou na criação de novos espaços públicos e na requalificação dos já existentes. Entende-se por "devolver o rio" permitir que a população usufrua dele e dos espaços públicos com a qualidade que thes é merecida retribuindo a importância, que desde sempre thes foi devida" (SOCIEDADE LEIRIAPOLIS, 2007: 17).
Este programa permitiu a criação de espaços verdes ao longo do espaço urbano sabendo que proporcionam uma melhoria na qualidade ambiental, bem como a construção de percursos pedonais e cicláveis. Por outro lado, apoiou intervenções na vertente de lazer e de recreio nas áreas adjacentes ao rio e, deste modo, revalorizar o rio e a paisagem urbana. 0 "contacto" entre a população e o rio veio conceder à cidade maior vitalidade, mais harmonia, segurança, conforto e beleza e que, de forma excecional tornaram a cidade mais digna, encantadora, atrativa, competitiva e funcional.

De modo a afirmar a competitividade de Leiria, o Programa Polis foi objeto de estudo, do qual resultou um Plano Estratégico (elaborado em 2000), que tinha como objetivo redesenhar a cidade de modo a "aproximar" a cidade ao rio Lis. Neste Plano Estratégico foram delimitados quatro objetivos (de acordo com a SOCIEDADE LEIRIAPOLIS, 2007) que pretendiam:

- Promover uma requalificação urbana efetiva orientada para a resolução das funcionalidades numa articulação positiva entre a cidade e o rio Lis repensando o papel da área de intervenção como parte da cidade e como catalisador de uma requalificação urbana mais extensa;

- Potenciar os valores fundamentais identificados nas valências histórica e ambiental, orientando a determinação de vocações coletivamente aceites e dirigindo as ações no sentido de conquistar uma população jovem de grande autonomia e mobilidade;

- Recuperar o rio Lis nas suas características qualitativas como elemento natural único permitindo a sua integração na vivência urbana como elemento lúdico, estruturante e de referência;

- Promover a imagem de Leiria através da renovada situação exemplar e diferenciada de valorização ambiental e requalificação urbana.

Desde a elaboração do plano estratégico até à conclusão das intervenções (2000-2008) foram eviden-

Quadro I

Planos de Pormenor do Polis em Leiria e respetivas áreas de intervenção

\begin{tabular}{|c|c|}
\hline Plano de Pormenor & Áreas de Intervenção \\
\hline S. Romão/Olhalvas "Sistema Rio" ( 43,1 ha) & $\begin{array}{l}\text { "Zona" } 1 \text { - São Romão; } \\
\text { "Zona" } 2 \text { - Quinta da Fábrica. }\end{array}$ \\
\hline St. ${ }^{\circ}$ Agostinho "Sistema Rio" (14,2 ha) & $\begin{array}{l}\text { "Zona" } 3 \text { - Ponte dos Caniços/Ponte Hintze Ribei- } \\
\text { ro/ Ponte Eng. }{ }^{\circ} \text { Afonso Zúquete. }\end{array}$ \\
\hline Leiria Centro "Sistema Rio" (28,9 ha) & $\begin{array}{l}\text { "Zona" } 4 \text { - Jardins/Marachão; } \\
\text { "Zona" } 5 \text { - Ponte Sá Carneiro/Ponte do Arrabalde; } \\
\text { "Zona" } 6 \text { - Ponte do Arrabalde/EN1 (IC2). }\end{array}$ \\
\hline Centro Histórico (38,2 ha) & "Zona" 7 - Zona Histórica. \\
\hline
\end{tabular}

Fonte: Adaptado de MAOT e POLIS, 2000: 50. 
tes as alterações na estrutura urbana de Leiria. A fim de materializar os objetivos e onde se "(...) desenvolve e concretiza propostas de organização espacial, definindo com detalhe a concepção da forma de ocupação e servindo de base aos projectos de execução das infraestruturas, da arquitectura dos edifícios e dos espaços exteriores" (MAOT e POLIS, 2000: 60), foram elaborados quatro planos de pormenor, num total de sete áreas de intervenção (Quadro I), "seis referentes aos Planos de Pormenor de Valorização e Requalificação do "Sistema Rio" e uma referente ao Plano de Pormenor da Zona Histórica" (MAOT e POLIS, 2000: 50).

O Plano de Pormenor S. Romão/Olhalvas (PP1) corresponde à área de mais periférica do espaço urbano de Leiria, de recente ocupação e onde ocorre a confluência da ribeira do Sirol com o rio Lis. O PP1 é constituído por duas "zonas" de intervenção, compreendendo a área envolvente ao rio Lis, desde a Ponte de São Romão até à Ponte dos Caniços. O Plano de Pormenor de St. ${ }^{\circ}$ Agostinho (PP2) diz respeito a uma das áreas da cidade de "(...) ocupação mais antiga, que remonta ao século XVII, época do estabelecimento das unidades moageiras na margem direita do rio Lis (...)" e de ocupação religiosa dada a existência do Convento de Santo Agostinho (MAOT e POLIS, 2000: 51). O PP2 considera a área a jusante da Ponte dos Caniços até à Ponte Eng. ${ }^{\circ}$ Afonso Zúquete. O Plano de Pormenor de Leiria Centro (PP3) foca-se numa área central da que dinamiza a cidade $e$

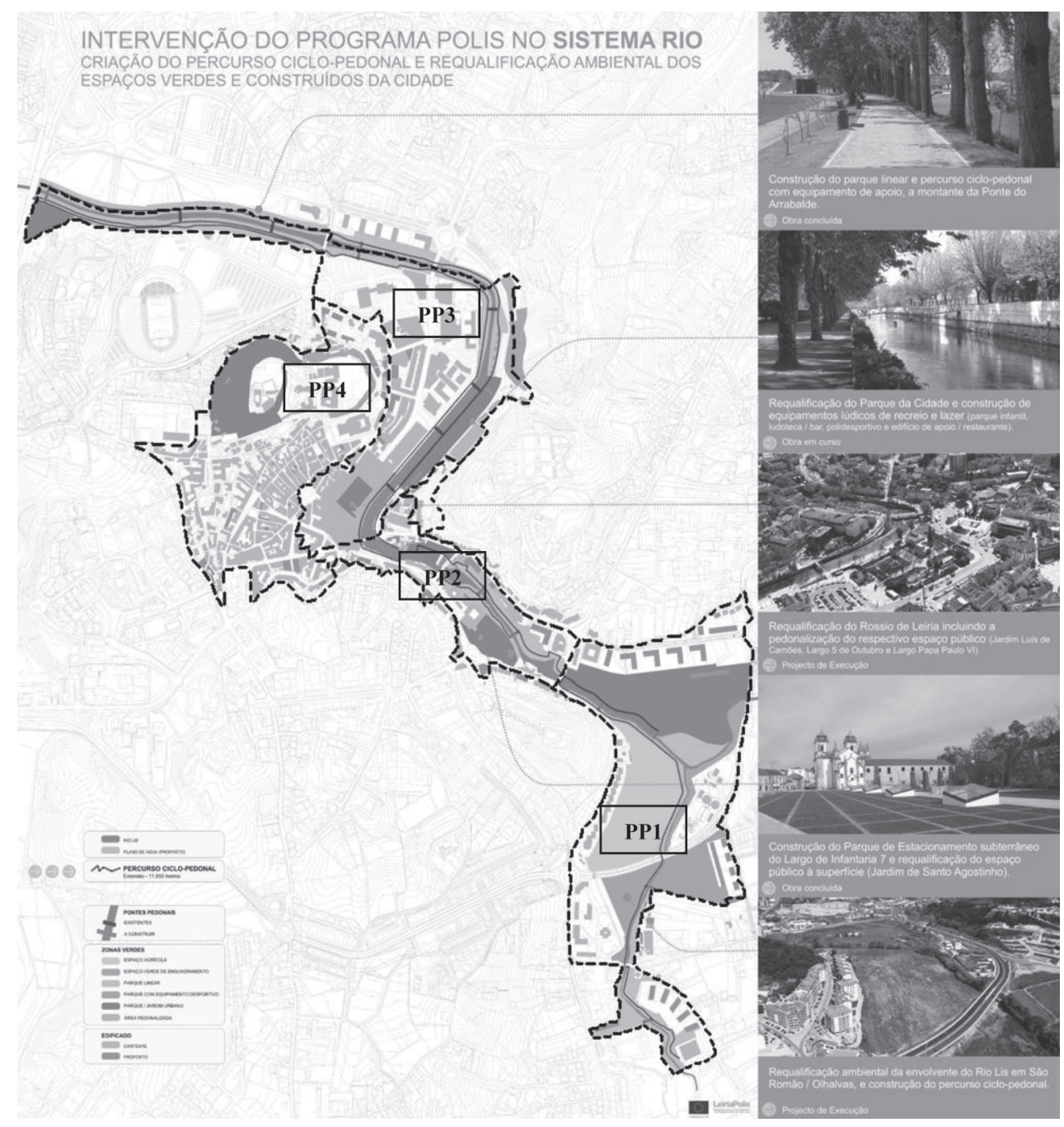

Figura 3

Localização dos Planos de Pormenor do Polis em Leiria

Fonte: Adaptado de http://www.skyscrapercity.com/showthread.php?t=600530, último acesso a 19 de Outubro de 2011. 
exerce pressão sobre o espaço envolvente. O PP3 integra três "zonas". O PP3 é limitado a partir da Ponte Eng. ${ }^{\circ}$ Afonso Zúquete até à Almoinha Grande. O Plano de Pormenor Centro Histórico (PP4) "(...) compreende o Núcleo Histórico da cidade de Leiria, (...) corresponde a uma zona de alto valor histórico, cultural e ambiental, integrando edificações de especial interesse arquitectónico e urbanístico (...)" (MAOT e POLIS, 2000: 52).

$\mathrm{Na}$ figura 3 pode ter-se uma visão de conjunto da área intervencionada no âmbito do Programa Polis em Leiria.

\subsection{Sentir e viver os territórios Polis}

De modo a elaborar uma análise exploratória (perspetivas dos utilizadores) em relação aos espaços existentes e ao contributo do programa para Leiria, foram realizadas entrevistas, a fim de recolher as opiniões da população nas sete áreas de intervenção, diferenciadas quanto à idade e ao género (Quadro II). Através das entrevistas foi possível observar o perfil do habitual utilizador nas sete áreas de intervenção, em função das horas e dos dias da semana/fim-se-semana. Para tal, foi necessário dedicar pelo menos um dia a cada área de intervenção (exceto nas "zonas" 1 e 2; 5 e 6 , dada a proximidade, o trajeto que estabelece a ligação entre as "zonas" em causa e as características em termos de intervenção).

Quem se desloca ao fim-de-semana à cidade e aos locais intervencionados pelo Polis, depara-se com o facto de os espaços serem frequentados por muita população residente da freguesia de Leiria, bem como das freguesias do concelho. Verifica-se uma crescente intensidade e movimento de utilizadores para áreas vocacionadas para o lazer, recreio e estada. Os leirienses adotaram novos estilos de vida, que passa cada vez mais pelo aproveitamento das potencialidades do espaço público, sobretudo para a prática de desporto. Contudo há muitos utilizadores que se deslocam a estas "zonas" também para conviver, conversar e descansar, ou seja, o Polis aproximou as pessoas, em resultado da criação e requalificação de espaços, que se tornaram mais atrativos e apelativos, garantindo sempre a existência e a não descaracterização de elementos que representam a herança urbana. A cidade é constituída por espaços socializados e estes por sua vez conduzem fortemente à humanização de novas áreas, criando novas territorialidades. A vivência destes espaços é um especto bastante importante, na medida em que condicionam o bem-estar individual, social, físico e psíquico dos usuários. Isto é, a população vai desenvolvendo sentimentos, afetividade, impressões, atitudes, hábitos em relação a um território e aos recursos que este oferece. A relação existente entre o Homem e o território leva ao surgimento de novas valências, novos contextos e dinamismos de vida durante a semana e ao fim-desemana, bem como reforça o aparecimento de novas centralidades dentro e fora da cidade (SILVA, 2011).

Com a intervenção do Programa Polis, a cidade ficou dotada de espaços mais acessíveis, infraestruturas, equipamentos urbanos e menos obstáculos. Perante esta realidade houve quem sugerisse a existência de postos distribuídos pela cidade com bicicletas, à semelhança da cidade de Aveiro, para a percorrer e conhecer melhor, bem como possibilitar a prática de exercício físico. Relativamente a esta proposta foi ainda mencionado que era interessante criar um percurso ciclável, por entre áreas históricas e marcantes da cidade, devidamente assinalado, bem como elaborar, divulgar e distribuir o roteiro, acompanhado das respetivas referências.

$\mathrm{Na}$ opinião de quem visita a cidade ou vive nela há pouco tempo, consideram que apesar de Leiria ser uma cidade pequena, mas com novas áreas de expansão, consegue-se distinguir as diferentes fases de urbanização e as (novas) centralidades dentro ou fora da cidade. Os indivíduos têm uma boa imagem da cidade, referindo que esta é atrativa e convidativa a percorrer

Quadro II

População entrevistada nas áreas de intervenção do Programa Polis em Leira

\begin{tabular}{|l|c|c|c|l|}
\hline \multicolumn{1}{|c|}{ Áreas de intervenção } & \multicolumn{2}{|c|}{ Género } & \multicolumn{2}{|c|}{ Idade } \\
\hline \multicolumn{1}{|c|}{ Masculino } & Feminino & \multicolumn{1}{|c|}{ Masculino } & \multicolumn{1}{|c|}{ Feminino } \\
\hline "Zona" 1 - São Romão; & 16 & 13 & $13-14 ; 17-20 ; 30 ; 32-33 ; 56-58 ; 64-65$. & $17-18 ; 29 ; 31-34 ; 37 ; 43 ; 49-50 ; 66$. \\
\hline "Zona" 3 - Ponte dos Caniços/Ponte Hintze Ribeiro. & 6 & 14 & $30 ; 32 ; 60 ; 67-68 ; 76$. & $\begin{array}{l}21 ; 33 ; 35 ; 45-46 ; 50 ; 57 ; 60 ; 63 ; 70 ; \\
77 ; 81 ; 83 .\end{array}$ \\
\hline "Zona" 4 - Jardins/Marachão. & 16 & 10 & $\begin{array}{l}17-18 ; 31 ; 45 ; 56 ; 58 ; 60 ; 62 ; 65 ; 67- \\
68 ; 70-72 ; 74 .\end{array}$ & $13 ; 15 ; 17 ; 28-29 ; 37 ; 46 ; 62 ; 66 ; 71$. \\
\hline $\begin{array}{l}\text { "Zona" 5 - Ponte Sá Carneiro/Ponte do Arrabalde; } \\
\text { "Zona" 6 - Ponte do Arrabalde/EN1. }\end{array}$ & 13 & 11 & $\begin{array}{l}17 ; 29 ; 32 ; 36 ; 49 ; 53-55 ; 58 ; 64 ; 69 ; \\
71 ; 73 .\end{array}$ & $\begin{array}{l}16 ; 24 ; 28 ; 34 ; 38 ; 45 ; 48 ; 54 ; 61-62 ; \\
67 .\end{array}$ \\
\hline "Zona" 7 - Zona Histórica. & 9 & 13 & $16-17 ; 35 ; 37 ; 68 ; 70 ; 75 ; 80 ; 82$. & $\begin{array}{l}15-17 ; 36 ; 43 ; 52 ; 57 ; 73-75 ; 77 ; \\
79 ; 81 .\end{array}$ \\
\hline
\end{tabular}

Fonte: SILVA, 2011. 
as frentes ribeirinhas e ao mesmo tempo, ter ao seu dispor espaços com diferentes funcionalidades, infraestruturas e equipamentos para diferentes públicos-alvo. Todavia, é evidente o descontentamento em relação ao vandalismo verificado ao longo de Leiria, não somente nas áreas Polis. É fundamental apelar à educação ambiental. Os jovens demonstram cada vez mais falta de civismo e sentido de responsabilidade por aquilo que o território possui. Segundo o Dr. Luís Matias, técnico superior principal da PSP de Leiria, quando se fazem obras, o objetivo é melhorar o ambiente, neste caso urbano e ambiental, bem como contribuir para a minimização de focos de criminalidade. Neste sentido, não se pode dizer que as situações de violência, criminalidade e vandalismo aumentaram, considera-se que se mantêm, pois não existe ideia contrária a essa tendência. Contudo, no âmbito do Polis, criou-se uma área propícia ao vandalismo por parte dos utilizadores (jovens) que pintam o Parque Radical em São Romão, nomeadamente o skate parque. Foi referido que, predominantemente o número de queixas na cidade de Leiria incide no centro histórico, relacionadas com a falta de cumprimento das horas de encerramento dos bares. E, pontualmente, verificam-se algumas situações de incivilidade (agressões e barulho) que se sucedem durante as atividades noturnas, devido ao estado de embriaguez dos utilizadores. Perante esta entrevista, comprovou-se que não existe paralelismo entre os novos espaços Polis na cidade e as situações de delinquência. Isto significa, que os espaços criados, requalificados e reformulados não são considerados novos focos de criminalidade dadas as suas funcionalidades e características físicas (SILVA, 2011).

A estética da cidade melhorou, no entanto a população mostrou ainda o seu desagrado em relação às habitações existentes no centro histórico da cidade, que se encontram em ruínas e em degradação. A população referiu que é necessário, apesar de já se verificar nalgumas áreas, a requalificação de edifícios de modo a trazer e a devolver a beleza à cidade, uma vez que, é considerada como muito vaidosa. 0 facto de a cidade ter brio na sua beleza, no que respeita a aspetos negativos na cidade (maioritariamente, os resultantes do Polis e por exigências dos diferentes arquitetos), investiu-se na aquisição e importação de mobiliário urbano cuja manutenção é demasiado cara. Circunstância que, contribuiu para que em muitas áreas da cidade haja, e tenha sido referido pela população, iluminação deficiente. Isto é, a sustentabilidade e a solidez do mobiliário urbano fazem toda a diferença na fruição dos espaços, visto que as lâmpadas são demasiado ca- ras, e este tipo de situações leva a que se "corte" na iluminação pois não existe capacidade financeira para contornar este problema e "dar luz" em todos as áreas. Logo, a população fica condicionada a usufruir dos espaços com a máxima segurança e tranquilidade. In sistindo neste problema, a população dá importância à falta de iluminação e não valoriza o tipo e a qualidade dos equipamentos (o exemplo mais evidente está relacionado com os postes de iluminação). O facto de terem existido fundos para utilizar não significa que seja admissível adquirir equipamentos de valor exorbitante quando se podia optar por adquirir mais barato e dispor de mais meios financeiros para a concretização plena de projetos, como é o caso da requalificação do centro histórico.

Denota-se ainda que, e também na opinião da população residente e visitantes, Leiria não dispõe de muitas alternativas em relação a transportes públicos. Ou seja, o sistema de transportes é deficitário, sobretudo ao fim-de-semana, condicionando a deslocação da população da cidade ou da população que se desloca para esta.

Em relação à movimentação dentro do espaço urbano, a população continua a referir que também existe uma escassez de transportes, e que por sua vez o sistema de transportes urbanos Mobilis é demasiado dispendioso. Quanto aos acessos à cidade do Lis, verificase uma escassez de alternativas, uma vez que durante a semana, em hora de expediente, sucedem-se situação de estrangulamento na circulação viária, sendo fundamental restringir o acesso às áreas mais centrais da cidade, bem como desenvolver um sistema de estradas, semelhante ao da variante sul, que se caracteriza por ser uma boa alternativa para quem se desloca à cidade ou desta em direção a outras áreas.

A aplicação do Polis em Leiria contribuiu para harmonização dos espaços com o rio e modificou o paradigma e as vivências da população através da criação de novas valências desportivas, de recreio, de estada e de lazer na cidade e no espaço urbano de Leiria. Facto que, segundo os entrevistados, permitiu uma melhoria na qualidade de vida e na saúde bem como torna a cidade mais inovadora, competitiva e atrativa (SILVA, 2011).

\section{Conclusão}

Em Portugal, a política de cidades e em particular a requalificação urbana foi assumida como área de intervenção prioritária em 2000-2006, na sequência de relevantes documentos orientadores e experiências 
inovadoras no contexto internacional, e ainda considerando os resultados de iniciativas realizadas no próprio país (de escala e dimensão diversas, com destaque para a intervenção em Lisboa Oriental, no âmbito da Exposição Mundial de 1998).

O Programa Polis é a expressão de maior visibilidade desta prioridade, com larga representação territorial e consideráveis meios financeiros envolvidos.

A aplicação do Polis em Leiria contribuiu para harmonização dos espaços com o rio e modificou o paradigma e as vivências da população através da criação de novas valências desportivas, de recreio, de estada e de lazer na cidade e no espaço urbano de Leiria. Facto que, segundo os entrevistados, permitiu uma melhoria na qualidade de vida e na saúde bem como torna a cidade mais inovadora, competitiva e atrativa.

Tendo em conta a análise espacial e as entrevistas realizadas, constatou-se que existe uma diferenciação dos utilizadores quanto ao género e idade, e ainda consoante as áreas de intervenção do Polis. Deparou-se que existem áreas mais vocacionadas para um público jovem, onde podem desfrutar de espaços desportivos e de recreio, como é o caso do Parque Radical de São Romão ("zona1") e o Parque da cidade ("zona 4"). De uma forma geral, também se constatou que numa área relativamente próxima do centro da cidade, entre a Ponte dos Caniços e a Ponte Afonso Zúquete ("zona3"), predominam os utilizadores com idades superiores a 55 anos, ou seja, trata-se de uma área ribeirinha afastada da agitação citadina. Ao longo desta área é possível gozar de tranquilidade, bem-estar e sentir-se próximo do rio daí a sua frequência por parte de quem sente necessidade de descansar. No caso do percurso ciclável e pedonal (ao longo da frente ribeirinha, desde a "zona 1 " até à "zona 6"), está direcionado para todo o tipo de público, independentemente da idade. Mas que, pontualmente, a partir das 17 horas é muito frequentado por uma população jovem e ativa, que após terminar o seu dia de trabalho desloca-se ao longo destas áreas para recarregar "baterias". É evidente a mudança de atitude para com a cidade e os espaços que esta oferece.

Apesar da valorização da cidade e de se tentar devolver e aproximar o rio à população, considera-se que existem espaços que não estão devidamente requalificados e equipados, na medida em que, falta uma infraestrutura de apoio às necessidades básicas (instalação sanitária e um edifício de restauração no Parque de São Romão) e alguns espaços carecem de equipamentos que propiciam a prática desportiva.

Ao longo de alguns espaços intervencionados pelo Programa Polis, mais precisamente nas "zonas 1 e 2" e no Jardim de St. ${ }^{\circ}$ Agostinho ("zona 3"), denota-se que o maior problema é a falta de manutenção dos espaços verdes e de um sistema de rega eficaz, e a deficiência na limpeza do rio e das suas margens. Outros aspetos, como a incivilidade e desrespeito verificados ao longo da cidade e espaço envolvente, só podem ser solucionados por cada um, através de uma mudança de atitude. Para incutir, sobretudo nos jovens, essa mudança, deveriam promover-se mais campanhas de sensibilização e coresponsabilização bem como implementar medidas penalizadoras.

A paisagem e a imagem da cidade mudou, mas mudou para melhor. 0 resultado final deste programa urbano é positivo. A cidade beneficiou na medida em foram melhorados espaços, desenvolveu-se um espírito positivo à população e à cidade que se fora perdendo ao longo dos anos e reforçou-se o apego destes à cidade. A intervenção Polis ajudou a consolidar a identidade dos leirienses, tendo-os também ajudado a saber viver a cidade.

Como eixos de orientação para futuras intervenções, consideramos da maior relevância as seguintes propostas: construção de um funicular; posto de acolhimento com disponibilização de um veículo que assegure o transporte até ao castelo, percorrendo áreas da cidade com interesse e história; requalificar e restaurar a Igreja de S. Pedro; construção de postos distribuídos pela cidade com bicicletas bem como um circuito ciclável devidamente acompanhado por um roteiro; requalificar e limpar as margens do rio; reforçar o sistema de transportes; deslocalização o terminal rodoviário; restringir o acesso às áreas mais centrais da cidade; construir um sistema de estradas alternativas de acesso à cidade.

\section{Bibliografia}

BeAujeu-Garnier, Jacqueline (1997) - Geografia Urbana. Fundação Calouste Gulbenkian, Lisboa, $2^{\text {a }}$ Edição.

Carvalho, Paulo (2003) - "Património Cultural e iniciativas de desenvolvimento local no espaço rural". In CAETANO, Lucília (coord.) - Território, do Global ao Local $e$ Trajectórias de Desenvolvimento. Centro de Estudos Geográficos, Coimbra, pp. 199-227.

Carvalho, Paulo (2008) - "Cidades e Valorização Paisagística de Frentes Aquáticas". Biblos, Volume VI ( $2^{\mathrm{a}}$ série), Coimbra, pp. 328-329.

Carvalho, Paulo (2012) - Ordenamento e Desenvolvimento Territorial. Imprensa da Universidade de Coimbra, Coimbra. 
CML (Câmara Municipal de Leiria) (2004) - "O concelho de Leiria e o contexto territorial". In I Revisão do Plano Director Municipal de Leiria, Câmara Municipal de Leiria, Leiria.

CML (Câmara Municipal de Leiria) (2011) - PALOR - Programa de Acção Local para a Regeneração Urbana do Centro Histórico de Leiria. Câmara Municipal de Leiria, Leiria.

Correia, Francisco Nunes (2007) - Intervenção do Programa Polis em Leiria. Sociedade LeiriaPolis, Leiria.

DGOTDU (Direcção Geral de Ordenamento do Território e Desenvolvimento Urbano) (2008) - Proposta de projecto de decreto regulamentar que estabelece conceitos técnicos a utilizar nos instrumentos de gestão territorial. DGOTDU, Lisboa.

Healey, Patsy (2007) - Urban Complexity and Spatial Strategies Towards a Relational Planning for our Times. Routledge, Taylor \& Francis e-Library, London and New York.

Henriques, Eduardo Brito (2004) - "O Património nas Políticas Territoriais". In Actas do V Congresso da Geografia Portuguesa - 'Portugal: Territórios e Protagonistas',
Disponivel: http://www.apgeo.pt/files/docs/CD_V Congresso_APG/web/_pdf/E5_140ut_Eduardo\%20 Brito\%20Henriques.pdf (data de acesso: 03 de Setembro de 2011).

MACIocco, Giovanni (2009) - "The Territorial Future of the City". Springer Science+Business Media B.V., Volume 3, pp. 1718.

MAOT (Ministério do Ambiente e Ordenamento do Território) e POLIS (2000) - Programa de Requalificação Urbana e Valorização de Cidades. MAOT, Lisboa.

MAOT (Ministério do Ambiente e Ordenamento do Território) e POLIS (2000) - Plano Estratégico. MAOT, Lisboa.

SıLVA, Ana Marina Ribeiro (2011) - Requalificação Urbana. O exemplo da Intervenção Polis em Leiria. Dissertação de Mestrado em Geografia Humana. Ordenamento do Território e Desenvolvimento, Universidade de Coimbra, Coimbra.

SOCIEDADE LEIRIAPOLIS (2007) - Intervenção do Programa Polis em Leiria. Sociedade LeiriaPolis, Leiria. 